\title{
Understanding the Pathophysiology of Neonatal Jaundice
}

\section{Yi-Hao Weng*}

Division of Neonatology, Department of Pediatrics, Chang Gung Memorial Hospital, Chang Gung University College of Medicine, Taiwan

Bilirubin mainly originates from heme via the catalyzation of heme oxygenase $(\mathrm{HO})$ and biliverdin reductase and is conjugated into direct form by UDP-glucuronosyl transferase (UGT1A1) for subsequent biliary secretion [1]. Jaundice develops when conjugated or unconjugated bilirubin deposits onto the skin. It is very common during the neonatal period. Neonatal jaundice is related to a variety of physiologic and pathologic conditions [2]. Physiologic aspects are comprised of increased bilirubin production, less efficient hepatic conjugation and enhanced enterohepatic circulation. In respect of pathologic situation, there are two patterns of diseases: hyperbilirubinemia and cholestassis. Hyerbilirubinemia refers to accumulation of unconjugated bilirubin beyond the extent of physiologic jaundice, while cholestasis results from the excretory obstruction of conjugated bilirubin.

Neonatal hyperbilirubinemia carries a potential risk of kernicterus, a long-term neurological impairment [3]. Proper management is of paramount important to avoid the complications. The traditional therapy is phototherapy and exchange transfusion [4]. Phototherapy is the mainstay of treatment, with exchange transfusion held in reserve for neonates with bilirubin encephalopathy. Despite its potential harm, unconjugated bilirubin has been proposed as an antioxidant. $\mathrm{HO}$ and biliverdin reductase might also play roles in the protection from oxidative stress for vulnerable neonates $[5,6]$.

Etiological verification is essential because the underlying diseases are critical factors of neurological sequelae [7]. There is a wide range of conditions that affect bilirubin levels, including environmental and genetic origins. These events may aggravate the destruction of red blood cells (e.g. cephalohematoma, hemolysis), delay the metabolism (e.g. prematurity) and increase the absorption of bilirubin (e.g. intestinal obstruction) [8]. Although breastfeeding is a major cause of neonatal hyperbilirubinemia, it dose not serve as a risk factor for kernicterus [7,9]. Instead, sepsis carries the greatest risk of poor outcomes.

The most important maternal effect on neonatal hyperbilirubinemia is isoimmune hemolytic disease. The clinical manifestation is early-onset hyperbilirubinemia with anemia [10]. $\mathrm{Rh}$ incompatibility displays more severe hyperbilirubinemia than $\mathrm{ABO}$ incompatibility. With the introduction of $\mathrm{Rh}$ immunoglobulin, the incidence of $\mathrm{Rh}$ isoimmune hemolytic disease has declined. By far $\mathrm{ABO}$ incompatibility is the most common cause of isoimmune hemolytic disease.

A large number of evidence has shown a correlation of neonatal hyperbilirubinemia with genetic factors, such as glucose-6-phosphate dehydrogenase (G6PD) deficiency and Gilbert syndrome (a genetic polymorphism of UGT1A1) [11]. G6PD deficiency is the most common genetic disorder in the world. Contact with naphthalene will induce neonatal hyperbilirubinemia in G6PD-deficient neonates [12]. Even in the environment free from agents that can potentially cause hemolysis, they are at greater risk of neonatal hyperbilirubinemia [13]. In addition, genetic interactions could enhance the severity of neonatal hyperbilirubinemia $[11,14]$.

Jaundice persists beyond 14 days of life can be a sign of neonatal diseases [15]. Cholestasis, such as biliary atresia, should be considered. Prompt intervention is essential for identification of biliary atresia that requires early operation. Nevertheless, the vast majority of neonates with prolonged jaundice are associated with breastfeeding. Both environmental and genetic factors are involved in the development of breast milk jaundice $[16,17]$.

Causation of neonatal jaundice carries a geographic difference. Challenge exists in the determination of causation. With an enthusiastic support for breastfeeding, it has become a leading cause of neonatal hyperbilirubinemia. There are complex interrelationships between and within genetic and environmental factors. Clinicians need to develop a systematic approach to identify the possible etiologies in relation to neonatal jaundice.

\section{References}

1. Dennery PA, Weng YH, Stevenson DK, Yang G (2001) The biology of bilirubin production. J Perinatol 21: S17-20.

2. Dennery PA, Seidman DS, Stevenson DK (2001) Neonatal hyperbilirubinemia N Engl J Med 344: 581-590.

3. Shapiro SM (2003) Bilirubin toxicity in the developing nervous system Pediatr Neurol 29: 410-421.

4. Weng YH, Chiu YW (2011) Comparison of efficacy and safety of exchange transfusion through different catheterizations: femoral vein versus umbilical vein versus umbilical artery/vein. Pediatr Crit Care Med 12: 61-64.

5. Weng YH, Yang G, Weiss S, Dennery PA (2003) Interaction between heme oxygenase-1 and -2 proteins. J Biol Chem 278: 50999-51005.

6. Sedlak TW, Snyder SH (2004) Bilirubin benefits: cellular protection by a biliverdin reductase antioxidant cycle. Pediatrics 113: 1776-1782.

7. Weng YH, Chiu YW, Cheng SW, Hsieh MY (2011) Risk assessment for adverse outcome in term and late preterm neonates with bilirubin values of $20 \mathrm{mg} / \mathrm{dL}$ or more. Am J Perinatol 28: 405-412.

8. Watchko JF (2012) Neonatal indirect hyperbilirubinemia and kernicterus In: Gleason CA, Devaskar SU (9th ed) Avery's Diseases of the Newborn. Elsevier Saunders.

9. Maisels MJ, Bhutani VK, Bogen D, Newman TB, Stark AR, et al. (2009) Hyperbilirubinemia in the newborn infant > or $=35$ weeks' gestation: an update with clarifications. Pediatrics 124: 1193-1198.

10. Weng YH, Chiu YW (2009) Spectrum and outcome analysis of marked neonatal hyperbilirubinemia with blood group incompatibility. Chang Gung Med J 32: 400-408.

11. Kaplan M, Renbaum P, Levy-Lahad E, Hammerman C, Lahad A, et al. (1997) Gilbert syndrome and glucose-6-phosphate dehydrogenase deficiency: a dose-dependent genetic interaction crucial to neonatal hyperbilirubinemia. Proc Natl Acad Sci U S A 94: 12128-12132.

*Corresponding author: Dr. Yi-Hao Weng, Division of Neonatology, Department of Pediatrics, Chang Gung Memorial Hospital, 199 Dunhua North Road, Taipei, Taiwan. Tel: + 886227135211 ext. 3427; Fax: + 8862 25457279; Email: yihaoweng@adm.cgmh.org.tw

Received February 09, 2012; Accepted February 15, 2012; Published February 19,2012

Citation: Weng YH (2012) Understanding the Pathophysiology of Neonatal Jaundice. J Neonatal Bio 1:e103. doi:10.4172/jnb.1000e103

Copyright: @ 2012 Weng YH. This is an open-access article distributed under the terms of the Creative Commons Attribution License, which permits unrestricted use, distribution, and reproduction in any medium, provided the original author and source are credited. 
12. Weng YH, Chiu YW (2010) Clinical characteristics of G6PD deficiency in infants with marked hyperbilirubinemia. J Pediatr Hematol Oncol 32: 11-14.

13. Weng YH, Chou YH, Lien RI (2003) Hyperbilirubinemia in healthy neonates with glucose-6-phosphate dehydrogenase deficiency. Early Hum Dev 71: 129-136.

14. Weng YH, Chou YH, Cheng ML, Chiu DTY (2002) Increased heme oxygenase-1 expression in glucose-6-phosphate dehydrogenase deficient human fibroblasts. Pediatr Res 51: 328A.
15. Hannam S, McDonnell M, Rennie JM (2000) Investigation of prolonged neonatal jaundice. Acta Paediatr 89: 694-697.

16. Chang PF, Lin YC, Liu K, Yeh SJ, Ni YH (2009) Prolonged unconjugated hyperbiliriubinemia in breast-fed male infants with a mutation of uridine diphosphate-glucuronosyl transferase. J Pediatr 155: 860-863.

17. Bozkaya OG, Kumral A, Yesilirmak DC, Ulgenalp A, Duman N, et al. (2010) Prolonged unconjugated hyperbilirubinaemia associated with the haem oxygenase-1 gene promoter polymorphism. Acta Paediatr 99: 679-683. 